Int. J. Electrochem. Sci., 14 (2019) 3968 - 3977

\title{
Pulse Potentiostatic Deposition of Polyaniline Nanobumps on 3D Graphene Hydrogel for High-Performance Supercapacitor Electrode
}

\author{
Yadong Wang ${ }^{l}$, Hanfang Feng ${ }^{l}$, Pei Dong ${ }^{1}$, Jun Shi ${ }^{l}$, Guixun Li $^{2,}{ }^{*}$, Li Zhang ${ }^{1, *}$
}

${ }^{1}$ School of Materials Science and Engineering, Zhengzhou University, Zhengzhou 450001, P. R. China ${ }^{2}$ Department of Civil Engineering Mechanics, Yellow River Institute of Hydraulic Research, Zhengzhou 450003, P. R. China

*E-mail: lizhang9@zzu.edu.cn (L. Zhang); liguixun@qq.com (G. Li)

doi: $10.20964 / 2019.04 .65$

Received: 6 January 2019 / Accepted: 22 February 2019 / Published: 10 March 2019

The facile pulse potentiostatic method (PPM) was employed to deposit polyaniline (PANI) nanobumps on the framework of hydrothermal graphene hydrogel $(\mathrm{GH})$ in this work. The obtained GH/PANI composite shows larger accessible surface area and higher electrochemical activity than the previous one by the potentiostatic method, thus resulting in the further improvement of electrochemical capacitive properties. The PPM GH/PANI composite exhibits a high specific capacitance $\left(864 \mathrm{~F} \mathrm{~g}^{-1}\right.$ at $\left.2 \mathrm{~A} \mathrm{~g}^{-1}\right)$, good rate capability $\left(66 \%\right.$ capacitance retention even at $\left.100 \mathrm{~A} \mathrm{~g}^{-1}\right)$, and excellent stability $(83 \%$ retention after 1000 cycles at $4 \mathrm{~A} \mathrm{~g} \mathrm{~g}^{-1}$ ). These results suggest a great advantage of PPM GH/PANI composite electrode for the high performance supercapacitor.

Keywords: Graphene hydrogel; Polyaniline nanobumps; Pulse potentiostatic method; Supercapacitor

\section{$\underline{\text { FULL TEXT }}$}

(C) 2019 The Authors. Published by ESG (www.electrochemsci.org). This article is an open access article distributed under the terms and conditions of the Creative Commons Attribution license (http://creativecommons.org/licenses/by/4.0/). 